\title{
Discurso político-acadêmico e integração das pessoas com deficiência: das aparências aos sentidos
}

\author{
POLITICAL AND ACADEMIC DISCOURSE AND INTEGRATION OF HANDICAPPED PEOPLE: \\ FROM LOOKING TO SENSES \\ DISCURSO POLÍTICO/ACADÊMICO E INTEGRACIÓN DE LAS PERSONAS CON DEFICIENCIAS: \\ DE LAS APARIENCIAS HASTALOS SENTIDOS
}

\author{
Inacia Sátiro Xavier de França ${ }^{1}$, Lorita Marlena Freitag Pagliuca ${ }^{2}$, Rosiléa Alves de Sousa ${ }^{3}$
}
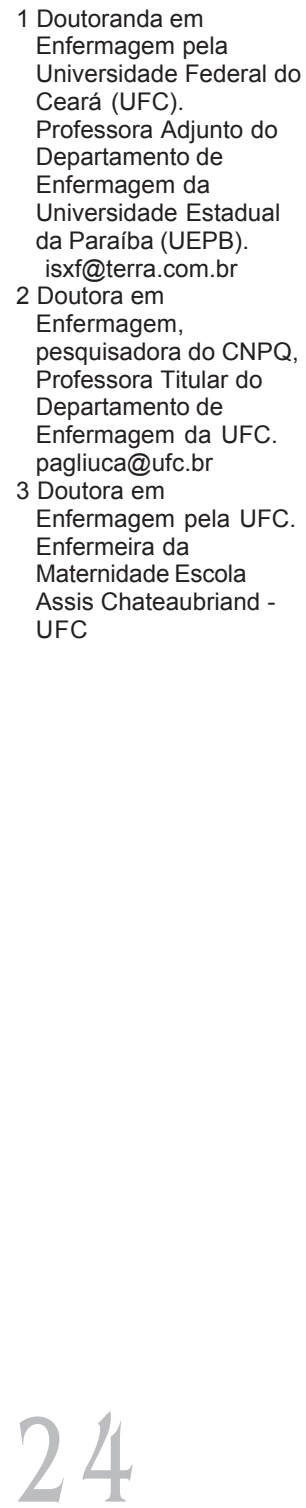

Rev Esc Enferm USP 2003; 37(4): 24-33

\author{
RESUMO \\ Objetivamos analisar o \\ Decreto 3.298/99 e os planos \\ das disciplinas dos Cursos de \\ Graduação em enfermagem \\ para verificar inclusão do \\ item participação do \\ enfermeiro no processo de \\ integração das Pessoas \\ Portadoras de Deficiência- \\ PPD. Lemos os planos das \\ disciplinas de quatro \\ universidades; recortamos as \\ disciplinas em comum e as \\ distribuímos conforme o nivel \\ de atenção em saúde. As \\ proposições do Decreto são \\ universais, igualitárias e \\ democráticas, os planos \\ encampam a maioria das \\ ações recomendadas pelo \\ Ministério da Saúde para \\ prevenir as deficiências, \\ contudo a prática acadêmica \\ exercita a prevenção- \\ tratamento, silenciando a \\ respeito da inserção do \\ Enfermeiro no processo de \\ integração da PPD.
}

\author{
ABSTRACT \\ Our aim was to analyze law \\ no. 3.298/99 and course plans \\ in undergraduate nursing \\ programs in order to confirm \\ the inclusion of the item for \\ participation of nurses in the \\ Handicapped People (HP) \\ integration process. We read \\ the plans of courses from four \\ universities; indentified the \\ courses in common and \\ distributed them according to \\ the level of health care. The \\ proposals of the law are \\ universal, equal, and \\ democratic; the plans of \\ courses analyzed adopt most \\ of the actions recommended by \\ the Ministry of Health in order \\ to prevent deficiencies. \\ Nevertheless, academic \\ practice exercises prevention/ \\ treatment of diseases, \\ silencing concern over the \\ insertion of nurse in the HP \\ integration process.
}

\section{RESUMEN}

El objetivo de esta investigación fue analiza el Decreto 3.298/99 y los planes de las asignaturas de los Cursos de Pre Grado en Enfermería, con el fin de verificar la inclusión del item participación del enfermero en el proceso de integración de las Personas Portadoras de Deficiencia (PPD). Leímos los planes de las asignaturas; seleccionamos las asignaturas en común y las distribuimos de acuerdo con el nivel de atención en salud. Las propuestas del Decreto son universales, igualitarias $y$ democráticas; los planes de los cursos analizados abarcan la mayoría de las acciones recomendadas por el Ministerio de Salud Pública para prevenir las deficiencias; no obstante la práctica académica ejercita la prevención-tratamiento de las enfermedades manteniendo en silencio lo referente a la inclusión del Enfermero en el proceso de integración de la PPD.

\author{
PALAVRAS-CHAVE \\ Enfermagem. Educação. \\ Socialização. \\ Pessoas portadoras de \\ deficiência. \\ KEYWORDS \\ Nursing. \\ Education. \\ Socialization. \\ Disabled persons.
}

\author{
PALABRAS CLAVE \\ Enfermería. \\ Educación. \\ Socialización. \\ Personas con discapacidad.
}




\section{INTRODUÇÃO}

O processo de globalização da informação provocou rupturas no universo das práticas sociais exigindo, das instituições e dos atores sociais, um repensar, um refazer e uma reestruturação das formas de produção do conhecimento. Os cursos de enfermagem, colocando-se na vanguarda desse movimento, vêm modificando a sua prática, tentando ajustar o seu projeto pedagógico às necessidades emergentes no contexto sócio-histórico. Essas formações discursivas nos chamaram a atenção para as questões relativas ao envolvimento do enfermeiro no processo de integração social das pessoas portadoras de deficiência (PPD).

Estudos publicados por Peto ${ }^{(1)}$, Silva ${ }^{(2)}$, Flávio; Zago ${ }^{(3)}$, Costa; Castro; Pagliuca ${ }^{(4)}$, Mancussi $^{(5)}$, Zerbetto; Rodrigues ${ }^{(6)}$, Neves; Comaru; Tonaki; Stigliano ${ }^{(7)}$ e Leite; Aguiar; Carvalho ${ }^{(8)}$, enfocam o cuidado às PPD e destacam a atuação do enfermeiro na fase aguda dos processos mórbidos que desencadeiam as limitações de ordem física, sensitiva ou mental. Contudo, ainda é diminuto o número de artigos que enfocam a participação do enfermeiro no processo de integração social das PPD. Ficamos a nos questionar: qual a razão para o reduzido número de publicações, em enfermagem, acerca do modo de ajudar as pessoas com necessidades especiais a se integrarem à sociedade? Por outro lado, as histórias de vida editadas, em nosso país, por pessoas com deficiência física, a exemplo de Paiva ${ }^{(9)}$, França $^{(10)}$, Machado $^{(11)}, \operatorname{Tormin}^{(12)}, \operatorname{Scotti}^{(13)}$, Barbosa $^{(14)}$, Júnior ${ }^{(15)}$ e Pecci ${ }^{(16)}$, mencionam a assistência que lhes foi prestada durante a fase de hospitalização, mas silenciam acerca de ações de saúde voltadas para a sua integração social. Mais uma questão nos ocorre: a grade curricular do curso de enfermagem oferece conteúdos que contemplem o processo de integração dessa clientela?

Foram essas indagações que nos motivaram a realizar esse estudo que objetivou analisar o Decreto 3.298 de 20 de dezembro de 1999 acerca da integração das PPD. Analisar os planos das disciplinas dos Cursos de Graduação em Enfermagem de universidades da região nordeste alcançando os componentes cabeçalho, ementa, objetivos, conteúdo programático, metodologia, avaliação e bibliografia sugerida para verificação da participação do enfermeiro no processo de integração da PPD.
A rota para a garimpagem do saber-fazer em enfermagem

Trata-se de um estudo descritivo, orientado por base documental. Elegemos, como universo da investigação, os Cursos de Graduação em Enfermagem de quatro universidades públicas e os Cursos de Graduação em Enfermagem de duas universidades particulares, situadas em dois estados do nordeste brasileiro.

Enviamos ofício à direção desses cursos solicitando permissão para o acesso às fontes de pesquisa mediante informação sobre os objetivos do estudo. Esclarecemos as instituições acerca do respeito aos princípios da beneficência, não maleficência, justiça e autonomia. No que se refere ao princípio da autonomia, asseguramos o respeito ao direito de privacidade, sigilo e de declinar a participação em qualquer momento da investigação.

Compusemos a amostra com os planos das disciplinas de três Cursos de Graduação em Enfermagem de três universidades públicas e de um curso de Graduação em Enfermagem de uma universidade particular, situados em dois estados nordestinos que nos responderam, afirmativamente, e enviaram os planos de disciplinas gravados em disquetes.

Quando da realização do estudo, situamos a perspectiva teórico-metodológica no campo da análise de discurso que visa compreender como um objeto simbólico produz sentidos. Nesse tipo de investigação os textos que compõem o corpus são discursos que mantém relação com a ideologia que permeia determinado tema. $\mathrm{O}$ analista seleciona o corpus orientando-se por critérios teóricos, desvinculandose de critérios positivistas, e atentando para a distinção entre o universo discursivo, o campo discursivo e o espaço discursivo(17).

No caso desse estudo, o corpus encampou: o universo discursivo - conjunto das formações discursivas acerca da integração das pessoas com necessidades especiais; o campo discursivo - recorte efetuado no universo discursivo, encampando o Decreto 3.298/99 e o conjunto dos planos das disciplinas dos períodos profissionalizantes do Curso de Graduação em Enfermagem de quatro universidades, situadas em dois estados da região nordeste, sendo três públicas e uma particular. E o espaço discursivo - confronto entre o discurso estatal veiculado pelo Decreto 3.298/99 e o
Discurso políticoacadêmico e integração das pessoas com deficiência: das aparências aos sentidos 
Inacia Sátiro X. de França Lorita Marlena F. Pagliuca Rosiléa Alves de Sousa discurso acadêmico incluso nos componentes: cabeçalho, ementa, objetivos, conteúdo programático, metodologia, avaliação e na bibliografia recomendada no plano das disciplinas estudadas.

Quando da análise, fizemos a correlação entre os planos das disciplinas e a instituição de origem denominando os quatro Cursos de A, B, C e D. Os planos das disciplinas analisados são relativos à programação dos semestres letivos dos anos 2000 e 2001.

Comparamos, por conteúdo específico e correlato, os planos das disciplinas dos quatro cursos A, B, C e D para compreender o seu funcionamento discursivo e apreender aqueles tópicos que privilegiassem a prevenção de deficiências, a reabilitação e a re-socialização das pessoas com deficiência. Para isso, tomamos por base as ações de atenção primária e secundária em saúde como medidas de prevenção de deficiências e recomendadas pelo Ministério da Saúde ${ }^{(18-19)}$.

Recortamos os planos das disciplinas comuns aos quatro cursos A, B, C e D, cuja ementa, objetivos e conteúdo programático estão direcionados para a prevenção primária e secundária da deficiência. $\mathrm{O}$ resultado foi apresentado no quadro 1 (prevenção primária) e 2 (prevenção secundária). A reflexão analítica se fez à luz do referencial bibliográfico. Os resultados do estudo estão expressos nos itens a seguir.

\section{Análise do discurso político contido no Decreto 3.298 e do discurso acadêmico inserido no plano das disciplinas}

Em 20 de dezembro de 1999 a Coordenação Nacional para Integração de Pessoa Portadora de Deficiência-CORDE conseguiu a sanção presidencial do Decreto 3.298 que regulamenta a Lei 7.853/89 e dispõe sobre a política nacional para integração social dessas pessoas. Este dispositivo legal recomenda o desenvolvimento de atividades no campo da saúde, da educação, da habilitação e reabilitação profissional, do acesso ao trabalho, da cultura, do desporto, do turismo e do lazer, para consolidar o processo integrador.

O Decreto, por si só, deixa transparecer que o processo de integração da PPD ainda é fato que requer bastante esforço político para ser consolidado. A evidência está estampada no Capítulo dos Princípios, Art. $5^{\circ}$, III que recomenda respeito às pessoas portadoras de deficiência, que devem receber igualdade de oportunidades na sociedade por reconhecimento dos direitos que Ihe são assegurados $^{(19)}$.

Assim dito, fica claro que existem rupturas e lacunas que obstacularizam o processo de integração das PPD, e isto nos leva a acreditar que a sociedade precisa desenvolver um processo amplo de informações acerca das potencialidades, dos direitos, das contribuições e das necessidades não satisfeitas desse segmento social. E, na medida em que todos os segmentos sociais compreenderem que todas as pessoas, deficientes ou não, possuem potencialidades que precisam ser desenvolvidas, e limitações que precisam ser respeitadas, é possível que a sociedade promova a re-significação do que seja uma PPD. Essa compreensão poderá desarmar os mecanismos de controle e abrir espaço para um novo discurso e novas práticas sociais em relação a PPD. É preciso, ainda, que o meio ambiente, a moradia, os transportes, os serviços de saúde e de educação, as dependências de trabalho, os locais de lazer, cultura e esporte tornem-se acessíveis para todas as pessoas, inclusive para aquelas com deficiência.

Na Seção II, "Do acesso a Educação", encontram-se, entre outros, o Art. 24 que estabelece

prioridade na matrícula compulsória em cursos regulares de estabelecimentos públicos e particulares de pessoa portadora de deficiência capaz de se integrar na rede regular de ensino.

O Art. 25 estabelece que

os serviços de educação especial serão ofertados (...) em escolas especializadas exclusivamente quando a educação das escolas comuns não puder satisfazer as necessidades educativas ou sociais do aluno ou quando necessário ao bem-estar do educando(19).

E o Art. 27 que

as instituições de ensino superior deverão oferecer adaptações de provas e os apoios necessários, previamente solicitados pelo aluno portador de deficiência, inclusive tempo adicional para realização das provas, conforme as características da deficiência ${ }^{(19)}$.
Rev Esc Enferm USP 2003; 37(4): 24-33. 
Os ditos desses artigos perseguem a universalidade, equidade e democratização do ensino como o modo de extinguir, de fato, a segregação das pessoas deficientes. Reconhece a escola regular como sendo o melhor ambiente pedagógico para este tipo de aluno, reservando a educação especial apenas para aqueles alunos considerados incapazes de integração na educação regular, desde que se faça necessário ao bem estar do educando. A necessidade de regulamentação da educação das PPD demonstra que a escola regular não está preparada para receber este tipo de aluno e, ao referir-se a necessidade de bem estar, o Decreto antecipa o conflito que permeia as relações sociais no âmbito da educação regular, quando acolhe o aluno deficiente. Esse aluno se expõe às práticas estigmatizantes que prejudicam a convivência com as demais crianças. Ao sinalizar o contraponto entre a educação regular e a educação especial, o Decreto deixa em suspenso que é preciso iniciar a integração desse educando desde a primeira infância, como o modo de sensibilizar os seus pares aos valores de tolerância e aceitação das diferenças.

A Seção III do Decreto trata da habilitação e reabilitação profissional. Aqui dois postulados se destacam: Art.30

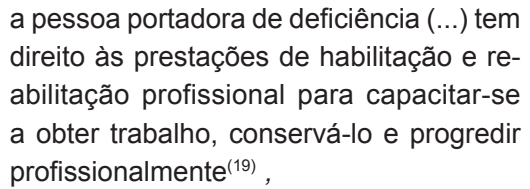
direito às prestações de habilitação e reabilitação profissional para capacitar-se a obter trabalho, conservá-lo e progredir profissionalmente(19),

e o Art. 33 que recomenda a reabilitação com base nas potencialidades da pessoa portadora de deficiência, considerando a educação escolar efetivamente recebida ou por receber, as expectativas de promoção social; as possibilidades de emprego existentes em cada caso, as motivações, atitudes e preferências profissionais e as necessidades do mercado de trabalho ${ }^{(19)}$.

Os sentidos do discurso político são democratizantes, bem intencionados, se propõem a oferecer os meios para que o deficiente se profissionalize, assegurando o acompanhamento por uma equipe multiprofissional. Contudo, o seu conteúdo antecipa os obstáculos que essa pessoa precisa enfrentar para se colocar no mercado de trabalho, tais como o desemprego e as exigências dos empregadores.

Na Seção IV, Art. 34, encontramos que a inserção da PPD no mercado de trabalho é uma prioridade e a sua incorporação ao sistema produtivo requer regime especial de trabalho protegido ${ }^{(19)}$. Entendemos que o não dito desse artigo relaciona-se com a resistência, oferecida pelas empresas, visando a não absorção dessa mão-de-obra. Essa resistência tem como causa o desconhecimento, pelos empresários, do potencial dessas pessoas. Essa situação foi confirmada por uma pesquisa ${ }^{(20)}$ que aponta as dificuldades para contratação desses trabalhadores, devido a falta de informação sobre as suas habilidades, de informação sobre onde recrutar essa mão de obra, de conhecimento técnico acerca do recrutamento. Antevendo esses obstáculos, o Decreto, em seu Art. 36, estabelece o percentual de PPD reabilitados que precisa ser contratado pelas empresas, conforme o quantitativo do seu quadro efetivo.

Na Seção V, Art. 46, o Decreto regulamenta as atividades pertinentes ao acesso da PPD a cultura, ao desporto, ao turismo e ao lazer. Nos ditos desse artigo, nos chamou atenção o parágrafo único:

\section{Os projetos culturais financiados com re- cursos federais, inclusive oriundos de programas especiais de incentivo à cultu- ra, deverão facilitar o livre acesso da pes- soa portadora de deficiência, de modo a possibilitar-Ihe o pleno exercício dos seus direitos culturais ${ }^{(19)}$.}

A construção de sentidos inscrita nesse parágrafo evidencia os obstáculos à integração dessas pessoas no âmbito das atividades propostas pelo Decreto. No campo da cultura, é preciso atender a algumas necessidades como equipamentos de comunicação para surdos, literatura em Braille ou cassetes para as pessoas com deficiência visual e, ainda, promover a participação em atividades de danças, música, teatro e artes plásticas. No campo do desporto, as dificuldades remetem à necessidade de instalações adequadas e de organização, além da valorização de tais atividades, dado que esse tipo de participação ainda é privilégio de algumas PPD, e os eventos desportivos só acontecem em algumas ilhas de excelência. Em relação ao acesso ao turismo e lazer, implica assegurar a utilização de restaurantes, cinemas, teatros, bibliotecas, locais de férias, praias, hotéis, estádios. À exceção das bibliotecas e dos estádios, a participação nos demais locais requer: condições financeiras adequadas, superação de precon-
Discurso políticoacadêmico e integração das pessoas com deficiência: das aparências aos sentidos 
Inacia Sátiro X. de França Lorita Marlena F. Pagliuca Rosiléa Alves de Sousa ceitos, por parte de alguns proprietários e freqüentadores desses locais. Por fim, o discurso estatal não contempla a inserção daquelas pessoas com problemas de ordem psiquiátrica.

Isto posto, passamos a analisar os Planos das disciplinas dos Cursos de Enfermagem denominados A, B, C e D, que fazem parte desse estudo, estabelecendo elos entre as disciplinas selecionadas e os postulados do Decreto 3.298, em sua Seção I - Da Saúde. O Art. 16 dessa Seção assim expressa:

\begin{abstract}
Os órgãos e as entidades da Administração Pública Federal direta e indireta responsáveis pela saúde devem dispensar aos assuntos objeto deste Decreto tratamento prioritário e adequado, viabilizando, sem prejuízo de outras, as seguintes medidas: promoção de ações preventivas, como as referentes ao planejamento familiar, ao aconselhamento genético, ao acompanhamento da gravidez, do parto e do puerpério, à nutrição da mulher e da criança, à identificação e ao controle da gestante e do feto de alto risco, à imunização, às doenças do metabolismo e seu diagnóstico, ao encaminhamento precoce de outras doenças causadoras de deficiência, e à detecção precoce das doenças crônico degenerativas e a outras potencialidades incapacitantes ${ }^{(19)}$.
\end{abstract}

Esse postulado direcionado aos órgãos e entidades assistenciais, também deve ser encampado pelo Ensino de Enfermagem, dado que, entre as funções desempenhadas pelo enfermeiro, figuram as atividades de atenção primária, secundária e terciária. Outrossim, o Decreto, em seu Art. 27, $\S 2^{\circ}$ expressa que o Ministério da Educação deverá expedir instruções para que

os programas de educação superior incluam nos seus currículos, itens ou disciplinas relacionadas à pessoa portadora de deficiência(19).

Entendemos que o currículo dos Cursos de Graduação em Enfermagem não pode prescindir de um plano de disciplina cujo conteúdo enfoque a prevenção de deficiência e a participação do enfermeiro no processo de reabilitação e integração social do deficiente. Daí o nosso interesse em analisar os planos das disciplinas de alguns Cursos de Graduação em Enfermagem, de universidades públicas e privadas, situadas na região nordeste do país, para compreender o porquê da apro- ximação/afastamento do enfermeiro do processo de integração das pessoas com necessidades especiais. Perseguindo o alcance desse objetivo, buscamos detectar nos planos das disciplinas a inclusão da atenção primária e secundária em saúde como medidas de prevenção de deficiências ${ }^{(18)}$ bem como de item direcionado para a integração da PPD.

A prevenção primária da deficiência diz respeito ao saneamento básico, condições de higiene pessoal e ambiental, fortalecimento dos vínculos familiares, renda adequada ao atendimento das necessidades básicas, nutrição balanceada e suficiente. Diz respeito, ainda, à vacinação, aos cuidados de puericultura, ao controle de gestação de alto risco, atenção à desnutrição da gestante e da criança, controle de fatores causadores de doenças crônicodegenerativas, ao uso de equipamentos de segurança no trabalho e no trânsito ${ }^{(19)}$.

A prevenção secundária tem relação com a detecção precoce, prevenção de incapacidades e intervenção imediata. O campo da detecção precoce requer avaliação clínica global da mulher e do bebê, exames para identificação de erros inatos do metabolismo, identificação de doenças infecto-contagiosa e crônico-degenerativas. O campo da prevenção de incapacidades e intervenção requer procedimentos imediatos e adequados para evitar e/ ou minimizar seqüelas, intervenção em berçários junto a bebês de alto risco e de crianças até três anos de idade, acompanhamento e estimulação do desenvolvimento infantil ${ }^{(19)}$.

No que diz respeito a atuação do enfermeiro no processo de integração social da PPD, entendemos que esse profissional precisa tomar parte ativa na equipe de reabilitação, incrementando ações educativas que ajudem essas pessoas a assumirem o autocuidado e a desenvolverem uma consciência transitiva crítica que facilite a sua reintegração social.

A análise dos planos das disciplinas à luz do Decreto 3.298 e do enunciado do Ministério acerca da prevenção da deficiência nos legou a seguinte compreensão:

O discurso acadêmico é um discurso do poder, preocupado com a transmissão de conhecimentos científicos. Por isso, no âmbito das instituições, esse discurso é homogêneo: os textos ostentam, no cabeçalho, o lugar ideológico onde se produz o dizer - Universi- 
dade, Centro, Departamento e Curso. Contudo, o que vale não é o local onde circula o discurso e sim a posição do sujeito que discursa. Eis porque o cabeçalho também ostenta a posição do sujeito - o professor o locutor encarregado de disseminar os discursos. Sua voz vale mais do que a do aluno (o ouvinte) porque ao falar, na posição de professor, entende-se que ele é o detentor do saber. A sua posição espelha o seu papel ensinar. O papel do aluno é aprender. Daí porque o discurso pedagógico

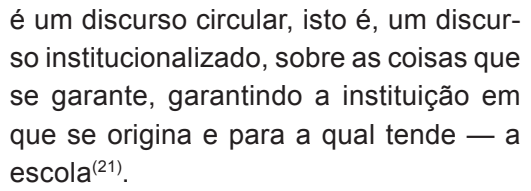

No cabeçalho, também se diz a denominação do conteúdo programático que constitui o tipo de discurso que deve ser enunciado ao longo do semestre letivo. Cada sujeito posicional apropria-se dos discursos de outros enunciadores e encarrega-se de fazer circular um tipo de discurso que lhe é específico como se o seu dizer não pudesse ser outro. Inscreve-se, também, no cabeçalho, a relação espaço-temporal, ou seja: o período le- tivo em que o discurso docente deve ser disseminado, conforme a compreensão da instituição acerca de que o discente já assimilou outros discursos que servirão de base a assimilação desse "novo" dizer, e o tempo necessário, em quantidade de horas, que deve durar o "novo" discurso docente. Buscamos explicação para essa prática e encontramos que

entre a imagem ideal do aluno (o que não sabe) e a imagem ideal do professor (o que tem a posse do saber e é legitimado pala esfera do sistema de ensino) há uma distância fartamente preenchida pela ideologia(21).

Dando continuidade à análise, lemos atentamente a ementa, os objetivos e o conteúdo programático dos planos das disciplinas dos cursos A, B, C e D, e pinçamos do campo discursivo, aqueles conteúdos cujas formações discursivas convergiam, sinalizando a informação de conhecimentos no campo da atenção primária e secundária das deficiências. A seleção dos discursos foi da seguinte ordem:

I. O discurso da prevenção primária (Quadro1)
Discurso políticoacadêmico e integração das pessoas com deficiência: das aparências aos sentidos

\section{Quadro 1 - A convergência do discurso da prevenção primária nos Cursos A,B, C e D}

\begin{tabular}{|l|l|}
\hline \multicolumn{1}{|c|}{ DISCIPLINA } & \multicolumn{1}{|c|}{ EMENTA } \\
\hline $\begin{array}{l}\text { I- Enfermagem em } \\
\text { Saúde Coletiva }\end{array}$ & $\begin{array}{l}\text { Conceitos básicos de saúde coletiva, saúde e cidadania. Estado } \\
\text { políticas públicas. Reforma sanitária. Epidemiologia socia } \\
\text { planejamento e programação de saúde. Modelos } \\
\text { técnico-assistenciais. Conformação do Sistema Único de Saúde } \\
\text { Atenção primária e educação em saúde. Ações de enfermagem nos } \\
\text { diferentes níveis do sistema de saúde na área coletiva. Classificaçã } \\
\text { das práticas de enfermagem em saúde coletiva. Doenças } \\
\text { transmissíveis; prevenção e tratamento nas unidades básicas d } \\
\text { saúde. }\end{array}$ \\
\hline $\begin{array}{l}\text { II - Saúde ambiental } \\
\text { A higiene ambiental e sua interação no processo saúde-doença } \\
\text { Aspectos culturais e sociológicos relacionados à saúde públice } \\
\text { Saneamento do meio ambiente: destino do lixo e dos dejetos } \\
\text { medidas de controle dos vetores e roedores e a relação destes } \\
\text { fatores no processo saúde-doença. }\end{array}$ \\
\hline $\begin{array}{l}\text { Obstetrícia } \\
\text { Aspectos anátomo-fisiopatológicos e psicológicos da mulher durant } \\
\text { a gravidez, trabalho de parto e puerpério. Aspectos nutricionais d } \\
\text { gravidez, puerpério e lactação. Identificação dos fatores de risco n } \\
\text { ciclo grávido puerperal e ginecológico. Aspectos preventivos } \\
\text { curativos e sociais na assistência global da mulher no cicl } \\
\text { grávido-puerperal. Fundamentação e implantação das ações básica } \\
\text { de saúde da mulher durante o pré-natal, trabalho de parto } \\
\text { puerpério e a participação da enfermagem no processo } \\
\text { assistencial.Promoção da assistência de enfermagem à mulher e } \\
\text { prevenção das complicações ginecológicas da menarca à menopausa } \\
\text { Assistência de enfermagem à mulher durante o ciclo } \\
\text { grávido-puerperal. }\end{array}$ \\
\hline
\end{tabular}


Inacia Sátiro X. de França Lorita Marlena F. Pagliuca Rosiléa Alves de Sousa
Correlacionamos cada uma das ementas com os seus objetivos e as unidades programáticas e chegamos a compreensão que o discurso disseminado pela Disciplina Saúde Coletiva nos quatro cursos apresenta alto grau de convergência: - objetiva instrumentalizar o graduando para o desempenho futuro nas atividades dos programas ministeriais, proporcionando-lhe uma visão global acerca da Reforma Sanitária no Brasil, dos programas ministeriais de Atenção à Saúde e do trabalho de enfermagem no âmbito desses programas.

A intenção discursiva da disciplina Saúde Ambiental é oferecer uma visão generalista da importância da higiene ambiental no processo saúde-doença, habilitar o graduando nas práticas de educação em saúde através de visitas e acompanhamentos domiciliares, identificar ações básicas relacionadas ao meio ambiente e sua influência no processo saúde-doença e compreender o mecanismo de transmissão das doenças.

Em relação ao discurso veiculado na disciplina Enfermagem em Obstetrícia, a intenção é capacitar o aluno a prestar assistência de enfermagem à mulher, no âmbito ginecoobstétrico, atuando naqueles processos de natureza normal ou patológica. A disciplina visa orientar os alunos na compreensão clínica, epidemiológica e social dos problemas de saúde que fazem parte da rotina dos serviços de saúde da rede básica e hospitalar, que afetam o binômio mãe-filho, caracterizar a situação de vida e a saúde da mulher durante o ciclo grávido-puerperal, e esclarecer as principais intercorrências clínicas e obstétricas durante a gravidez, parto e puerpério. Visa, ainda, fundamentar a sistematização e implementação das ações básicas de assistência integral à saúde da mulher durante o pré-natal de baixo risco, parto normal e puerpério imediato institucionalizado, particularizando o papel do enfermeiro e capacitar o(a) acadêmico(a) de enfermagem para atuar nos programas de assistência materna durante o pré-natal, na sala de partos, no puerpério, e no planejamento das gravidezes futuras.

É preciso relatar que detectamos disciplinas direcionadas para a prevenção primária que não tinham lugar comum em todos os cursos. Por isso, deixamos de inseri-las no quadro 1. Estas disciplinas foram: a) Fundamentos de nutrição (Curso A), cujos ditos têm relação com a importância da boa alimentação para a saúde orgânica, função e efeitos causados no organismo, pela carência ou ingestão excessiva dos alimentos, identificação das necessidades nutricionais do organismo nos períodos de crescimento e desenvolvimento, na idade adulta e na terceira idade; b) Epidemiologia (Curso A) que veicula o discurso da vigilância em saúde e o desenvolvimento de ações de enfermagem no âmbito do Programa Nacional de Imunizações; c) Tópicos especiais de enfermagem (Curso B), que propõe-se à reflexão acerca da assistência integral à saúde da família e sobre a participação do profissional de saúde no processo saúde-doença no contexto do Programa de Agentes Comunitários de Saúde.

II. O discurso da prevenção secundária (Quadro 2)

Quadro 2 - A convergência do discurso da prevenção secundária nos Cursos A, B, C e D

\begin{tabular}{|l|l|}
\hline \multicolumn{1}{|c|}{ DISCIPLINA } & \multicolumn{1}{|c|}{ EMENTA } \\
\hline $\begin{array}{l}\text { I - Enfermagem } \\
\text { Clínica }\end{array}$ & $\begin{array}{l}\text { Necessidades de saúde do indivíduo adulto e idoso no seu context } \\
\text { sócio-cultural. Estudos das doenças transmissíveis no context } \\
\text { sócio-econômico cultural do país, com ênfase naquelas mais comuns no } \\
\text { região nordeste. Assistência de enfermagem no atendimento das } \\
\text { necessidades humanas básicas do cliente adulto nos contexto } \\
\text { preventivo, curativo, de recuperação e reabilitação da saúde }\end{array}$ \\
\hline $\begin{array}{l}\text { II - Enfermagem } \\
\text { em Saúde da } \\
\text { Adolescente }\end{array}$ & $\begin{array}{l}\text { Assiantência de enfermagem à criança sadia, nas diversas faixas etária } \\
\text { Assistência de enfermagem a criança portadora das patologias ma } \\
\text { comuns no meio nordestino.Ensino, assistência, pesquisa e extensã } \\
\text { nos aspectos de promoção, proteção e reabilitação da Saúde da Crianç } \\
\text { em todas as faixas etárias. }\end{array}$ \\
\hline $\begin{array}{l}\text { III - Enfermagem } \\
\text { em emergências }\end{array}$ & $\begin{array}{l}\text { Prevenção de acidentes. Situações de urgência e emergência } \\
\text { pré-hospitalar. Suporte básico de vida. Metodologia de Assistência } \\
\text { Enfermagem, frente a situações de emergência. }\end{array}$ \\
\hline
\end{tabular}


O discurso em Enfermagem Clínica nos quatro cursos tem o seguinte enfoque: oferecer conhecimentos teórico - práticos para atuar em nível profilático e epidemiológico na área de doenças transmissíveis, aplicar esse conhecimento em nível ambulatorial e hospitalar, planejar, executar e avaliar a assistência de enfermagem sistematizada ao portador de doenças transmissíveis, família e comunidade, nos três níveis de atenção à saúde.

No contexto da disciplina Enfermagem em Saúde da Criança e do Adolescente, o discurso se propõe a disseminar conhecimentos relacionados com a conservação da saúde da criança, utilizar a metodologia da assistência de enfermagem individualizada, centrada no estágio de desenvolvimento e nas reações da criança frente à hospitalização.

A disciplina Enfermagem em Emergência objetiva capacitar o aluno para a assistência à vítima em situação de emergência, discernindo os cuidados imediatos dos mediatos. Por fim, os quatro cursos desenvolvem estágios supervisionados em hospitais, ambulatórios e na comunidade, objetivando que o aluno aprimore o conhecimento e as habilidades adquiridas em sala de aula.

Algumas disciplinas apresentam objetivos centrados no professor, conforme demonstram os seguintes exemplos: "Treinar os alunos para o desenvolvimento de habilidades..." "Capacitar o discente para..." E são poucos os objetivos que abrangem uma perspectiva de análise crítica do processo saúde-doença, como é o caso dos seguintes objetivos:

\footnotetext{
Reconhecer os diversos modos do organismo humano responder ao processo saúde-doença.

Identificar sinais e sintomas sociais, mentais, emocionais e físicos relacionados ao comprometimento dos diversos sistemas orgânicos.
}

Os conteúdos, em sua maioria, encampam uma abordagem atualizada da área estudada e apresentam uma seqüência lógica, priorizando os aspectos técnicos. Alguns conteúdos estão centrados em dados anatomo-físiológicos e nos distúrbios e desequilíbrios orgânicos em detrimento de algum objetivo que priorize aspectos sócio-políticos o que denota incoerência entre o conteúdo e este objetivo traçado.
As representações que emergem da nossa análise têm correlação com a função da escola como agente de reprodução cultural:

o sistema de ensino é a solução mais dissimulada para o problema da transmissão de poder, pois contribui para a reprodução da estrutura das relações de classe dissimulando, sob a aparência da neutralidade, o cumprimento dessa função (...) dissocia sua função de reprodução cultural de sua função de reprodução social, aparecendo como colaboradora que harmoniza a transmissão de um patrimônio cultural que aparece como bem comum ${ }^{(21)}$.

No que concerne a Enfermagem, o discurso acadêmico, tanto no campo da atenção primária como na secundária, encampa as ações preconizadas pelo Ministério da Saúde para prevenir a deficiência. Contudo, inexiste, nos planos de disciplinas analisados, um item que enfoque a participação do enfermeiro no processo de integração social da PPD. Essa lacuna no processo de formação do enfermeiro contribui para o não despertar, dos profissionais e graduandos, para esse campo de atuação. A conseqüência natural é o número diminuto de publicações envolvendo essa temática.

Em relação à metodologia de ensino, apreendemos o predomínio de uma pedagogia de tendência liberal, particularmente da tradicional, centrada na fala e no saber do professor e na verticalização da relação professor-aluno. A avaliação da aprendizagem se dá por meio de provas escritas para assegurar a fixação mental dos conhecimentos e de prova prática para verificação da habilidade e destreza para realização de procedimentos técnicos no campo de estágio. Desse modo, é ponto comum no plano das disciplinas a "Avaliação do desempenho nas atividades teórico-práticas". Esse tipo de discurso "cria a noção de erro e, portanto, o sentimento de culpa..."(21) pois nem sempre o aluno corresponde às expectativas do professor que avalia. Nesse tipo de educação bancária o professor é "uma voz segura e auto-suficiente... a estratégia, a posição final, aparece como o esmagamento do outro"(21). Essa tendência pedagógica pode acarretar conseqüências do tipo

\footnotetext{
passividade do aluno, a falta de atitude crítica grande absorção de informação, falta de questionamento e de problematização, individualismo, falta de participação e cooperação, falta de conhecimento da própria realidade, imitação de padrões intelectuais, artísticos e institucionais ${ }^{(22)}$
}

Discurso políticoacadêmico e integração das pessoas com deficiência: das aparências aos sentidos 
Inacia Sátiro X. de França Lorita Marlena F. Pagliuca Rosiléa Alves de Sousa porque as avaliações enfatizam as questões objetivas, em detrimento de questões subjetivas que estimulam o desenvolvimento de uma consciência crítico-reflexiva.

A bibliografia sugerida nos planos das disciplinas, de modo geral, oferece possibilidades de uma abordagem técnica e, ao mesmo tempo, crítica, demonstrando uma relação entre objetivos, conteúdos e bibliografia.

A análise do modo de construção do saber no âmbito do processo de formação dos profissionais de Enfermagem revela que a profissionalização desses sujeitos está atrelada às idéias do taylorismo (a ideologia da divisão do trabalho) e do fordismo (a ideologia da produção em série). Tanto assim é que a produção do conhecimento de Enfermagem prioriza aqueles aspectos internos da profissão, sinalizando um "alheamento" em relação ao processo de formação do enfermeiro. A práxis acadêmica permanece reproduzindo os interesses da classe dominante, pautando-se em modelos e normas sociais de comportamentos propagadores das idéias sócio-políticas do contexto histórico dado. Por isso, persiste a construção de conhecimentos com o sentido de procurar a causa das doenças, atuando sobre o corpo, sadio ou doente, controlando-o, disciplinando os indivíduos, reproduzindo a prática social e legitimando a perpetuação da ordem social.

A universidade tem como função reproduzir as relações de produção que asseguram a continuidade existencial da formação social, encarregando-se de reproduzir as forças produtivas e as relações de produção existentes nos seus diferentes cargos e empregos. Adquire-se um saber dito científico, utilizável nos diferentes locais de produção e, junto com esse saber, um conjunto de regras morais, uma ética profissional que se constituem, no seu conjunto, regras de respeito à divisão social e técnica do trabalho, regras da ordem estabelecida pela dominação de classe $^{(23)}$. Desse modo, o discurso acadêmico constitui o saber, o sujeito e o objeto do saber. A palavra institui a coisa. A linguagem, enquanto discurso, forma os objetos de que fala, institui a ideologia. $\mathrm{Na}$ escola aprende-se o métier

\section{Um último dizer}

Entendemos que o Decreto 3.298/99 é recente e este é um dos motivos porque os Cursos de Enfermagem analisados não contemplam, em seus planos de disciplinas, itens relacionados com a integração social das pessoas com necessidades especiais. Também não contemplam um programa de atuação junto a equipe multidisciplinar para ajudar essas pessoas a se integrarem à sociedade.

Por outro lado, entendemos que a educação é um processo de relações humanas, uma atividade interativa entre quem ensina e quem aprende. Esse processo implica além de competência teórico-prática, uma pedagogia sensibilizadora cujo viés é o compromisso político-social. A nossa compreensão é de que o enfermeiro tem grande contribuição a dar no processo educativo-integrador dessas pessoas, orientando-as para o autocuidado no atendimento das suas necessidades bio-psico-sócio-espirituais. Por isso, acreditamos que a adoção de estágio em instituições destinadas a integração da PPD proporcionaria ao graduando o estabelecimento de relações informais, manter contatos intergrupais, atuar em função das necessidades da pessoa cuidada, além de maior percepção da realidade, poder de argumentação, e mais autonomia para futuras decisões profissionais. Uma pedagogia dessa ordem transita pela esfera da transdisciplinaridade. Em outras palavras: requer uma linha de ação que estabeleça sintonia com os demais profissionais de saúde, indivíduo, família e comunidade, guiada pelo objetivo comum de motivar o outro para se comprometer com a sua qualidade de vida. O desenvolvimento de habilidades de auto-ajuda que o capacitem ao enfrentamento da doença e/ou das adversidades cotidianas, como condição sine qua non para a promoção da saúde e do bem-viver. 
(1) Peto AC. Terapia através da dança com laringectomizados: relato de experiência. Rev Lat-Am Enferm 2000; 8(6):35-9.

(2) Silva AMF. Refletindo sobre a qualidade de vida do portador de deficiência: resgatando os direitos de cidadão. Texto Contexto Enferm 1999; 8(3):88-98.

(3) Flávio PGC, Zago MMF. "Como se tivesse ganho na loteria": o significado da reabilitação vocal na visão de um paciente laringectomizado. Rev Lat-Am Enferm 1997; 5(3): $19-25$.

(4) Costa EM, Castro DN, Pagliuca LMF. Assistência de enfermagem: percepção da pessoa cega - reflexão sobre a ética e solidariedade. Rev Bras Enferm 1999; 52(4):615-23.

(5) Mancusi AC. Assistência ao paciente/família na situação de lesão traumática da medula espinhal. Rev Lat-Am Enferm 1998; 6(4): 67-73.

(6) Zerbetto SR, Rodrigues ARF. Relacionamento não diretivo do enfermeiro com paciente em processo de ressocialização. Rev Lat-Am Enferm 1997; 5 (n. esp.):77-83.

(7) Neves TA, Comaru MN, Tonaki AO, Stigliano E. O papel do(a) enfermeiro(a) do trabalho na reinserção social da pessoa com deficiência. Rev Bras Enferm 1982; 35:192-9.

(8) Leite JL, Aguiar RCB, Carvalho ML. A relação de ajuda a um grupo de clientes com problemas de locomoção. Rev Bras Enferm 1981; 34:211-23.

(9) Paiva MR. Feliz ano velho. 13 ed. São Paulo: Mandarim, 2001.

(10) França ISX. (Re)socialização da pessoa com deficiência adquirida: o processo, os personagens e as máscaras. João Pessoa: (sm) 2000.

(11) Machado WCA. Minha prisão sem grades: uma abordagem semiótica de reabilitação em enfermagem. Goiânia: Kelps, 1999.

(12) Tormin G. Pássaro sem asas. 4 ed. Goiânia: Kelps, 1999.

(13) Scotti L. A doce sinfonia do seu silêncio. São Paulo: O Nome da Rosa, 1999.

(14) Barbosa RM. E a vida continua. Maceió: Bom Conselho, 1998.

(15) Júnior RL. Longo caminho de volta. 4 ed. São Paulo: FTD, 1995.
(16) Pecci JC. Minha profisssão é andar. São Paulo: Summus, 1980

(17) Orlandi EP. Análise de discurso: princípios e procedimentos. Campinas: Pontes; 2001.

(18) Ministério da Saúde. Coordenação de Atenção a Grupos Especiais. Programa de Atenção à Saúde da Pessoa Portadora de Deficiência. Brasília: Ministério da Saúde; 1993.

(19) Ministério da Saúde. Coordenação Nacional para Integração da Pessoa Portadora de Deficiência. Brasília: Ministério da Saúde; 1999.

(20) Carreira D. A integração da pessoa deficiente no mercado de trabalho. In: Mantoan TEM, organizadoras. A integração de pessoas com deficiência: contribuições para uma reflexão sobre o tema. São Paulo: Memnon Editora SENAC; 1997. p. 24-31.

(21) Orlandi EP. A linguagem e seu funcionamento: as formas do discurso. $4^{\mathrm{a}} \mathrm{ed}$. Campinas: Pontes; 2001.

(22) Bagnato MHS. Concepções pedagógicas no ensino de enfermagem no Brasil. Texto e Contexto Enferm 1997; 6(3):241-58.

(23) Althusser L. Aparelhos ideológicos de estado: notas sobre os aparelhos ideológicos de Estado. 7 ed. Rio de Janeiro: Graal; 1989.
Discurso políticoacadêmico e integração das pessoas com deficiência: das aparências aos sentidos 